\title{
Mucormycosis and chromoblastomycosis occurring in a patient with leprosy type 2 reaction under prolonged corticosteroid and thalidomide therapy
}

\author{
Mucormicose e cromoblastomicose em um paciente com reação hansênica tipo \\ II sob terapia prolongada com corticosteróide e talidomida
}

\author{
Flávia Machado Alves Basílio ${ }^{1}$ \\ Maira Mitsue Mukai ${ }^{2}$ \\ Rosângela Lameira Pinheiro ${ }^{4}$
}

\author{
Mariana Hammerschmidt ${ }^{1}$ \\ Betina Werner ${ }^{3}$ \\ Sandra Moritz ${ }^{5}$
}

\begin{abstract}
Mucormycosis is an uncommon fungal infection caused by Mucorales. It frequently occurs in patients with neutropenia, diabetes, malignancy and on corticoid therapy. However, it is rare in patients with AIDS. Clinical disease can be manifested in several forms. The case reported illustrates the rare occurrence of chromoblastomycosis and mucormycosis in an immunosuppressed patient with multibacillary leprosy, under prolonged corticosteroid and thalidomide therapy to control leprosy type 2 reaction. Neutrophil dysfunction, thalidomide therapy and work activities are some of the risk factors in this case. Chromoblastomycosis was treated by surgical excision and mucormycosis with amphotericin $\mathrm{B}$. Although the prognosis of mucormycosis is generally poor, in the reported case the patient recovered successfully. This case should alert dermatologists to possible opportunistic infections in immunosuppressed patients. Keywords: Chromoblastomycosis; Immunocompromised host; Leprosy; Mucormycosis
\end{abstract}

Resumo: Mucormicose é uma infecção fúngica incomum causada por Mucorales. Ocorre frequentemente em pacientes com neutropenia, diabetes, corticoterapia e condições malignas. Porém, é rara em pacientes com AIDS. A doença pode apresentar-se em diferentes formas. Este caso ilustra a rara ocorrência de mucormicose e cromoblastomicose em um paciente com hanseníase multibacilar, que estava sendo tratado com prednisona e talidomida devido a eritema nodoso (reação hansênica tipo II). Disfunção de neutrófilos, uso de talidomida e atividades profissionais são alguns fatores de risco neste caso. A cromoblastomicose foi tratada por excisão cirúrgica e a mucormicose com anfotericina B. Embora o prognóstico da mucormicose seja ruim, neste caso o tratamento foi bem sucedido. Este caso alerta dermatologistas para a possibilidade de infecções oportunistas em pacientes imunossuprimidos.

Palavras-chave: Cromoblastomicose; Hanseníase; Hospedeiro imunocomprometido; Mucormicose

\section{INTRODUCTION}

Mucormycosis is an emerging life-threatening infection caused by Mucorales (Rhizopus, Rhizomucor, Absidia, Mucor, Cunninghamella). Given the ubiquitous nature of these fungi (found in soil and in decaying matter), most humans are expo- sed to these organisms on a daily or weekly basis. Nonetheless, they rarely cause disease because of their low virulence, mainly affecting individuals with immunosuppressed conditions. ${ }^{1}$

Chromoblastomycosis is a chronic disease cau-

\footnotetext{
Received on 25.08.2011.

Approved by the Advisory Board and accepted for publication on 09.11.2011.

* Study carried out at the Teaching Hospital of the Federal University of Paraná (Hospital de Clínicas da Universidade Federal do Paraná (HC-UFPR) - Curitiba (PR), Brazil Conflict of interest: None Financial funding: None

MD, Resident in Dermatology - Federal University of Paraná (Universidade Federal do Paraná - UFPR) - Curitiba (PR), Brazil.

Assistant Professor of Dermatology, Federal University of Paraná (Universidade Federal do Paraná - UFPR) - Curitiba (PR), Brazil.

Dermatopathologist - Federal University of Paraná (Universidade Federal do Paraná - UFPR) - Curitiba (PR), Brazil.

Biologist/Mycologist at the Teaching Hospital of the Federal University of Paraná (Hospital de Clínicas da Universidade Federal do Paraná (HC-UFPR) - Curitiba (PR), Brazil.

Dermatologist, Member of the Brazilian Society of Dermatology - São Paulo (SP), Brazil. 
sed by traumatic inoculation of saprophagous dematiaceous fungi, when they enter through an open wound and infect both skin and subcutaneous tissue. This disease is mostly reported in tropical and subtropical areas (higher in rural populations) and is often caused by Fonsecaea (F) pedrosoi. Countries with the highest numbers of cases are Madagascar and Brazil. ${ }^{2}$

The case reported illustrates the rare occurrence of chromoblastomycosis and mucormycosis in an immunosupressed patient with multibacillary leprosy, under prolonged corticosteroid and thalidomide therapy to control leprosy type 2 reaction.

\section{CASE REPORT}

A 28 year-old white male, rebar setter, born in Itaperuçu-PR and residing in Curitiba-PR/Brazil, was diagnosed with leprosy and neuritis in 2001, confirmed by skin biopsy (Figure 1). He was being treated with multibacillary chemotherapy and prednisone 1 $\mathrm{mg} / \mathrm{kg}$ since May 2001. Three months later, he developed flu-like symptoms. Rifampin was discontinued and dapsone and clofazimine were maintained. Erythema nodosum appeared in May 2002, and thalidomide was added to the treatment. In April 2003, at the end of the multibacillary chemotherapy, dapsone and clofazimine were suspended. During this time the patient was kept on prednisone and thalidomide to control neuritis and leprosy type 2 reaction (both drugs were suspended only in 2007).

In August 2003, he had a single erythematous, hyperkeratotic plaque with black dots on his right hand (Figure 2). A skin biopsy demonstrated large pigmented muriform cells inside multinucleated giant cells and Fonsecaea pedrosoi was isolated from the fungi culture (Figure 3). Chromoblastomycosis was diagnosed and treated by surgical excision, with total resolution. Erythema nodosum and neuritis persisted, and increased doses of both prednisone $(80 \mathrm{mg} / \mathrm{d})$ and thalidomide $(300 \mathrm{mg} / \mathrm{d})$ were necessary.

In December 2003, six nodular, non-tense, warm and erythematous lesions were noticed on his thighs and trunk (anterior and posterior). Systemic complaints were absent and blood analysis was normal, except for an elevation of serum glucosis $(229 \mathrm{mg} / \mathrm{dl})$. HIV test (ELISA) was negative. Seven days later, a yellow-greenish fistulization replaced the first lesions and new ones appeared. Skin biopsy of a left thigh lesion showed acute and chronic inflammation with broad dermal necrosis; secondary vasculitis was seen focally and fungi were not detected. A PAS- stained pus smear with diastase highlighted broad, pleomorphic, non-septated hyphae with irregular, non-parallel contours (Figure 4). Mucor $s p$ was isolated from the culture.

Treatment was started with parenteral amphotericin $\mathrm{B} 1 \mathrm{mg} / \mathrm{kg} / \mathrm{d}$ (total dose $=1880 \mathrm{mg}$ ) with con-

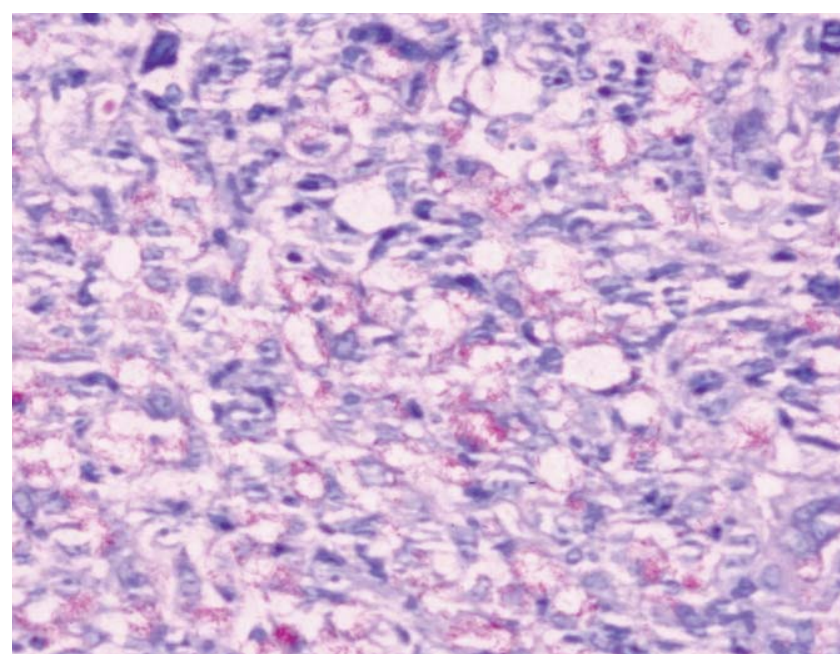

FIGURE 1: Skin biopsy - Leprosy diagnosis. Dense infiltrate of histiocytes containing large amount of Mycobacterium leprae in the cytoplasm. Fite Faraco $\mathrm{x} 400$ (original magnification)

comitant serum glucose control. Surgical drainage was performed in the larger lesions. Prednisone was tapered during this period. The patient was discharged from the hospital with only skin scars in the previously involved areas (Figure 5).

In February, 2004, the patient returned with papular lesions, plaques and fever. A new biopsy of a thigh lesion revealed virchowian leprosy and Lucio's phenomenon (necrotizing erythema). Modified multibacillary chemotherapy was started, with dapsone, clofazimine and ofloxacin (due to rifampin intolerance), and was finished after 24 months of treatment, in March, 2006.

During follow-up, patient had been free from lesions or reactional states since July, 2006, and last negative bacterioscopy was in December, 2008. Outpatient treatment was finished in January, 2010.

\section{DISCUSSION}

Mucormycosis is described in several clinical forms, with rhinocerebral disease affecting the paranasal sinus orbits and the brain (80\% to $90 \%$ of cases). ${ }^{1}$ The pulmonary, disseminated, cutaneous, and gastrointestinal forms are less common. The major route of infection is via inhalation of fungal spores; other routes include ingestion and traumatic inoculation. ${ }^{3}$

The cutaneous form (shown in this case) is less common than other clinical forms, but potentially lethal if early treatment is not started. It is usually related to local trauma, with several cases described after the use of adhesive bandages and invasive catheters contaminated by spores. Two different presentations of primary cutaneous mucormycosis have been described. The superficial form appears as vesicles or pustules that ulcerate with scar formation, usually in healt- 

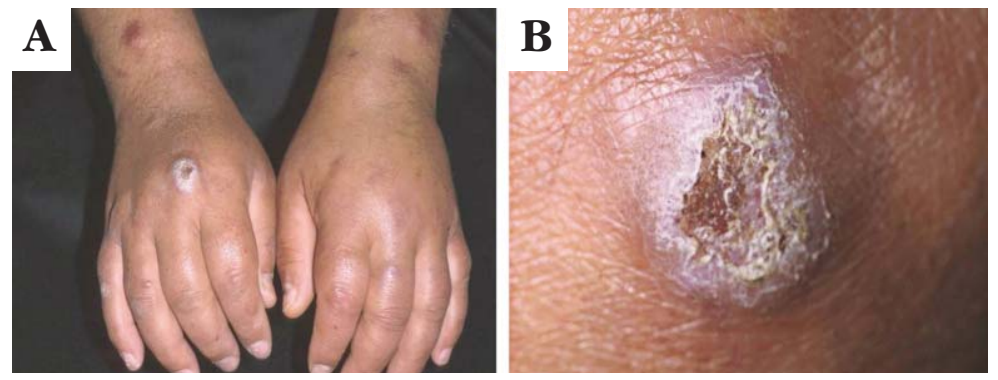

Figure 2: A and B. Chromoblatomycosis lesion. Single erythematous, hyperkeratotic plaque with black dots on the right hand

hy hosts. Rapidly progressing ulceration and dissemination in patients with decreased immunity are described in the gangrenous form. After inoculation, the fungus invades the skin and appears as a small discolored area that becomes black and necrotic with surrounding erythema. ${ }^{4}$

The risk factors for mucormycosis (neutropenia, diabetes mellitus with high glucose and metabolic acidosis, prolonged corticoid therapy, history of deferoxamine therapy in dialysis, hematologic malignancy) suggest that multiple cell types and mechanisms are responsible for the innate immunity against this organism. Neutrophils play the major role and individuals with neutropenia or neutrophil dysfunction are more susceptible, while cell-mediated immunity has a minor contribution. Nevertheless, it is uncommon in patients with AIDS. ${ }^{3,5}$

The defense mechanisms against mucormycosis are not well understood. After inhalation, alveolar macrophages, neutrophils and serum factors, like transferrin, may contribute to the damage of fungal spores, and sufficient levels of iron increase the fungus proliferation and tissue penetration ability. ${ }^{6}$

A skin biopsy and direct mycology exam should

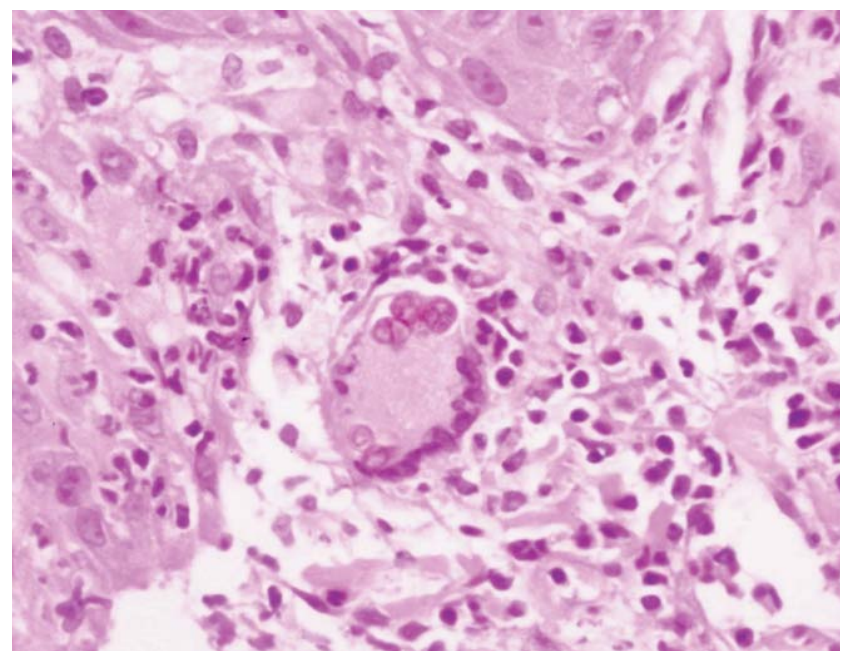

FIGURE 3: Skin biopsy: Chromoblastomycosis diagnosis Granulomatous inflammation with giant cell containing large pigmented muriform cells of Chromoblastomycosis in the cytoplasm. H.E. x400 (original magnification) be obtained in order to identify the hyphae and culture can identify the causative organism. Vascular invasion is a hallmark of zygomycosis, commonly associated with thrombosis of vessels and necrosis of surrounding tissue. ${ }^{4,6}$

The mucormycosis treatment approach should begin with primary prevention, including careful use of immunosuppressive therapy in patients whose condition demand the use of such agents. Correction of predisposing factors such as hypoalbuminemia, hypogammaglobulinemia, neutropenia, and hyperglycemia are also recommended. ${ }^{6}$

Amphotericin B is the antifungal agent of choice against mucormycosis. The recommended dose is $1 \mathrm{mg} / \mathrm{kg} / \mathrm{d}$ and the duration of treatment is between 3 and 6 weeks. ${ }^{3,5}$ Lipossomal amphotericin presents reduced nephrotoxic effect and improved cell penetration. ${ }^{5}$ Besides, recent data suggest that posaconazole may be useful as salvage therapy, and adjunctive immune therapy with recombinant granulocyte colony-stimulating factor (G-CSF) and GM-CSF, or with recombinant IFN- $\gamma$, has been used successfully in conjunction with lipid formulations of amphotericin $B$ in treatment of mucormycosis. ${ }^{5,}$

An iron chelator, deferasirox, does not allow iron utilization by the fungus and has been used as an

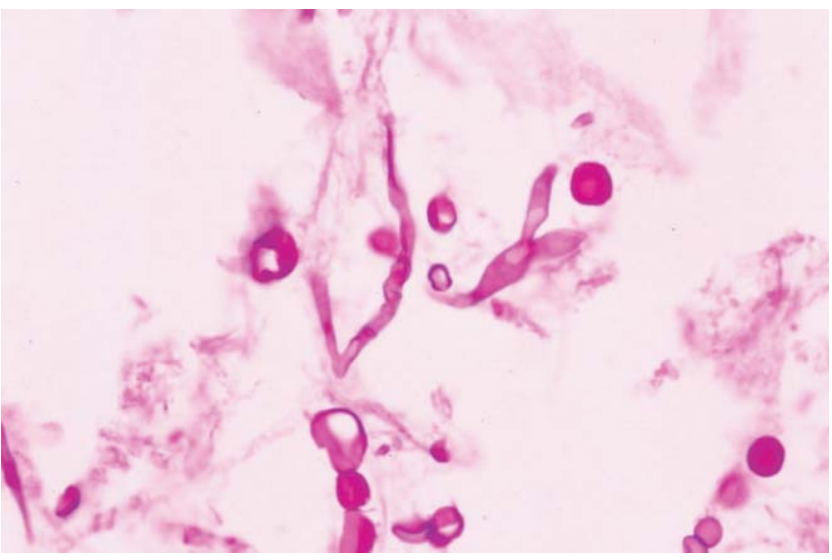

Figure 4: Mucormycosis diagnosis. A smear taken from skin lesion secretions showed large irregular and right-angle branched hyphae with large ovoid conidia of Mucormycosis. PAS with diastase x400 (original magnification) 


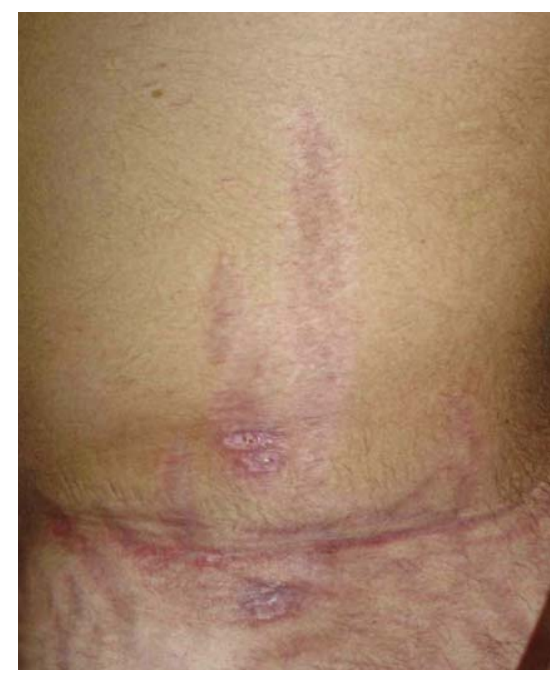

Figure 5: Cutaneous Mucormycosis - skin scars. The patient was discharged from the hospital with only skin scars in previously involved areas

agent for infection treatment, unlike deferoxamine that is a risk factor, since it allows the fungus to utilize deferoxamine-bound iron by recognizing it as a siderophore. $^{8}$

Furthermore, early and repeated surgical debridement of the involved tissues associated with an antifungal agent is an important part of the treatment and hyperbaric oxygen may be useful as an auxiliary treatment in cutaneous and rhinocerebral mucormycosis. ${ }^{3,5,7}$

Chromoblastomycosis is primarily a disease of tropical or subtropical regions, mainly in people working outdoors in agricultural occupations. The characteristic lesion is the warty papule or plaque eventually leaving a fibrotic scar.

The disease spreads in the adjacent skin with characteristic, satellite lesions surrounding the primary source. The lesions develop slowly at the site of implantation. Over the years, the nodule grows centrifugally. In many instances, the central parts of the lesion heals, leaving ivory-colored scars. Mortality due to chromoblastomycosis is a rare event. ${ }^{9}$

The diagnosis is based on $\mathrm{KOH}$ examination, identification of organism in histological sections and culture of the organism, which reveal slow growth of green to black colonies, and microscopic analysis of the conidia may identify the agent. A skin biopsy usually shows hyperkeratotic pseudoepitheliomatous hyperplasia with neutrophilic granulomatous reaction in the dermis. Pigmented large fungi are easily seen when stained with $\mathrm{H} \& \mathrm{E}$. ${ }^{1,9}$

Chromoblastomycosis lesions are recalcitrant and extremely difficult to eradicate. Chemotherapy (especially itraconazole), surgical excision and/or cryosurgery have been used throughout the years, but an effective treatment has not yet been established. Recent studies provide evidence that the HIV PIs (nelfinavir and saquinavir) have multiple effects on crucial biological processes of F. pedrosoi, showing the possibility of exploiting HIV PIs as a potential therapeutic agent, alone or in combination with currently used antimycotic drugs, in chromoblastomycosis. ${ }^{10}$

Reported cases of mucormycosis in literature include several clinical conditions, but none was described in association with leprosy.

In this case, the patient had some risk factors to development of mucormycosis, such as: prolonged corticosteroid therapy, which has negative effects on neutrophilic granulocytes (although the number of these cells is enhanced), causing impaired margination, reduced chemotactic activity, affecting phagocytosis and intracellular killing by neutrophils; thalidomide therapy, leading to diminished TNF alfa production and suppressed Th1 response; his profession, rebar setter, includes activities for steel reinforcement for concrete structures in which there is contact with sharp edges, iron and wood materials in a damp environment, the perfect place for fungi reproduction. This way, probably traumatic inoculation of fungal spores was the route of infection for both mucormycosis (multiple lesions) and chromoblastomycosis (single lesion).

Patients with leprosy are not susceptible to infections caused by Mucorales, as the neutrophil functions remain intact. However, the immunosuppressive effects of the therapy used to control reactional states may increase the prevalence of such infections. Probably the patient would not have the two diseases if he were not under prolonged corticosteroid and thalidomide therapy. In addition, work activities may have contributed significantly to mucormycosis and chromoblastomycosis infections in this case.

Mucormycosis has a high mortality rate and the survival outcome depends on early diagnosis, followed by an effective and aggressive treatment.

Although the prognosis of mucormycosis is generally poor, in the reported case the patient recovered successfully.

This case alerts dermatologists to possible infections occurring in immunosuppressed patients. A high index of suspicion is warranted in order to perform an early diagnosis and treatment, and better prognosis. 


\section{REFERENCES}

1. Kontoyiannis DP, Wessel VC, Bodey GP, Rolston KV. Zygomycosis in the 1990s in a tertiary-care cancer center. Clin Infect Dis. 2000;30:851-6.

2. Kim DM, Hwang SM, Suh MK, Ha GY, Choi GS, Shin J, et al. Chromoblastomycosis Caused by Fonsecaea pedrosoi. Ann Dermatol. 2011;23:369-74.

3. Yeung CK, Cheng VC, Lie AK, Yuen KY. Invasive disease due to Mucorales: a case report and review of the literature. Hong Kong Med J. 2001;7:180-8.

4. Oh D, Notrica D. Primary Cutaneous mucormycosis in infants and neonates: case report and review of the literature. J Pediatr Surg. 2002;37:1607-11.

5. Spellberg B, Walsh TJ, Kontoyiannis DP, Edwards J Jr, Ibrahim AS. Recent advances in the management of mucormycosis: from bench to bedside. Clin Infect Dis. 2009;48:1743-51

6. Mok CC, Que TL, Tsui EYK, Lam W. Mucormycosis in systemic lupus erythematosus. Semin Arthritis Rheum. 2003;33:115-24.

7. Sun HY, Singh N. Mucormycosis: its contemporary face and management strategies. Lancet Infect Dis. 2011;11:301-11.

8. Lewis RE, Pongas GN, Albert N, Ben-Ami R, Walsh TJ, Kontoyiannis DP. Activity of Deferasirox in Mucorales: Influences of Species and Exogenous Iron. Antimicrob Agents Chemother. 2011;55:411-3.
9. Queiroz-Telles F, Esterre P, Perez-Blanco M, Vitale RG, Salgado CG, Bonifaz A. Chromoblastomycosis: an overview of clinical manifestations, diagnosis and treatment. Med Mycol. 2009;47:3-15.

10. Palmeira VF, Kneipp LF, Rozental S, Alviano CS, Santos ALS. Beneficial effects of HIV peptidase inhibitors on Fonsecaea pedrosoi: promising compounds to arrest key fungal biological processes and virulence. PLOS ONE. 2008;3:e3382.

\author{
MAILING ADDRESS: \\ Flávia Machado Alves Basilio \\ Rua General Carneiro, 181 \\ Alto da Glória \\ 80060 -900 Curitiba, PR \\ E-mail: flavia_mab@yaboo.com.br
}

How to cite this article: Basilio FMA, Hammerschmidt M, Mukai MM, Werner B, Pinheiro RL, Moritz S. Mucormycosis and Chromoblastomycosis occurring in a patient with leprosy type 2 reaction under prolonged corticosteroid and thalidomide therapy. An Bras Dermatol. 2012;87(5):767-71. 